\title{
Polybenzocrown ethers: synthesis by cesium-assisted cyclization and solid-state structures
}

\author{
Robert E. Hanes, Jr., ${ }^{\text {a* Edward C. Ellingsworth, }}{ }^{\text {b Scott T. Griffin, }}{ }^{\text {b }}$ Robin D. Rogers, ${ }^{\text {b }}$ \\ and Richard A. Bartsch \\ ${ }^{a}$ Beacon Sciences, LLC, 11412 Bee Cave Rd., Austin, TX 78738 \\ ${ }^{b}$ Department of Chemistry and Center for Green Manufacturing, The University of Alabama, \\ Tuscaloosa, AL 35487 \\ ${ }^{c}$ Department of Chemistry and Biochemistry, Texas Tech University, Lubbock, TX 79409-1061 \\ E-mail: rhanes@beaconsciences.com
}

DOI: http://dx.doi.org/10.3998/ark.5550190.0011.717

\begin{abstract}
A series of large-ring polybenzocrown ethers is prepared by cesium-assisted cyclizations. Reactions of diphenols/bisphenols, dimesylates of oligoethylene glycols and cesium carbonate in $\mathrm{MeCN}$ produce the large-ring polybenzocrown ethers in high yields. To gain further insight into the structures of these compounds, solid-state structures of three large-ring crown ethers are obtained by X-ray diffraction.
\end{abstract}

Keywords: Cesium effect, macrocyclization, solid-state structures, crown ethers

\section{Introduction}

Increasing the number of benzo substituents in a crown ether framework can significantly alter the properties of the ligand. Generally speaking, adding benzo substituents will increase the rigidity of the crown ether framework and enhance lipophilicity, but decrease the basicity of the oxygens attached to the aromatic rings. ${ }^{1}$ Although Pedersen synthesized many examples of crown ethers with different numbers of benzo substituents in large-sized crown ether rings, many of the yields were very poor. Cesium-assisted cyclization has been found to be a viable method for the synthesis of monobenzocrown ethers (vide infra). ${ }^{2}$ Therefore, the preparation of multibenzocrown ethers by Pedersen's Method W strategy ${ }^{1}$ (Scheme 1), but with a cesiumassisted cyclization protocol (diphenols, dimesylates and cesium carbonate in $\mathrm{MeCN}$ ) was explored. 

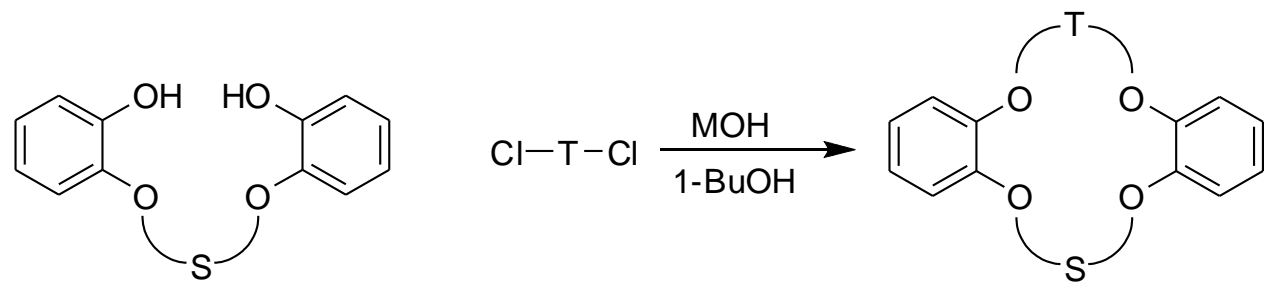

Pedersen's Method W

Scheme 1. Method W as described by Pedersen in reference 1.

Development of a Method W approach for the synthesis of di-, tri- and tetrabenzocrown ethers required the preparation of the bisphenol precursors. Tribenzo-18-crown-6 (6) and tribenzo-21-crown-7 (8) were selected as the initial multibenzocrown ether targets (Scheme 2). This pair of crown ether compounds was chosen because a common dimesylate reactant could be used for both ring closure reactions. Further, since these crowns were originally reported by Pedersen, it would allow for a direct comparison of yields obtained by the new method.

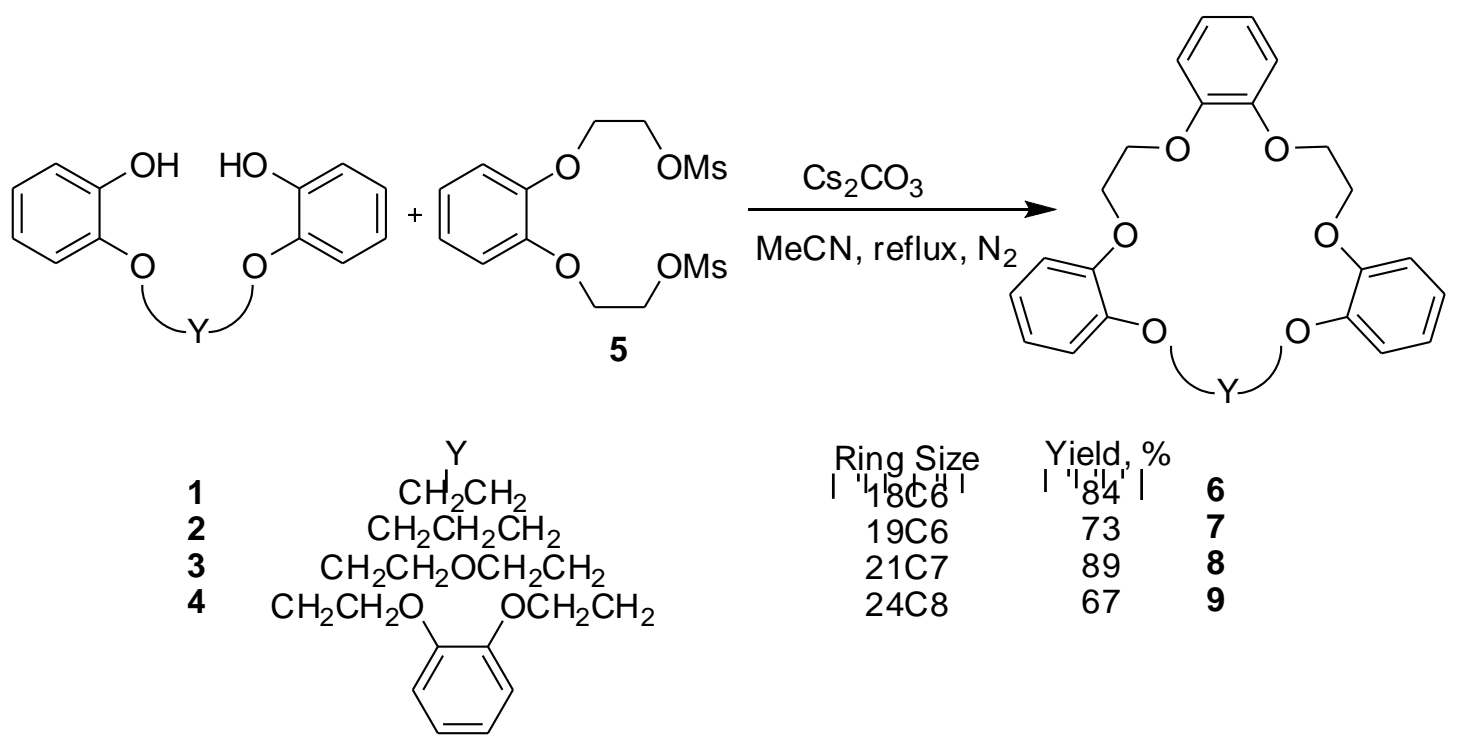

Scheme 2. Methodology for preparation of polybenzocrown ethers.

This paper summarizes our efforts to improve the synthesis of polybenzocrown ethers 6-9 and their precursors. To better understand how these ligands would function as cation complexants, their free-ligand, solid-state structures were determined by X-ray diffraction. The crystal structure of $\mathbf{6}$ as the acetonitrile solvate $(6 \cdot \mathbf{M e C N})^{3}$ and the structure of 9 have already been reported. 4 


\section{Results and Discussion}

Numerous methods for the preparation of crown ethers have been reported. ${ }^{5-10}$ Most commonly employed methods utilize a 'template effect' by matching the size of the crown ether cavity formed with the diameter of an appropriate templating cation. The obvious challenge presented with these reactions is the formation of the macrocycle instead of oligomeric side products. Most often high dilution conditions are employed, but this necessarily limits the reaction scale and increases cost by requiring large volumes of organic solvents. For the present work, indirect high dilution conditions were employed through the use of a syringe pump.

Using relatively concentrated solutions (0.045 $\mathrm{M}$ in bisphenol, $0.090 \mathrm{M}$ in dimesylate) slow addition of the dimesylate via syringe pump provided a means through which the solution concentration of the electrophile was low, favoring cyclization over oligomerization. The diol precursor to the targeted dimesylate 5 was prepared by modifying a reported procedure. ${ }^{11}$

With the starting materials in hand, cesium-assisted ring closures were attempted for the synthesis of the tribenzocrown ethers. After purification, tribenzo-18-crown-6 (TB18C6, 6) and tribenzo-21-crown-7 (TB21C7, 8) were obtained in 84 and 85\% yields, respectively. These yields are remarkable when compared to the yields of 28 and 19\% reported by Pedersen for TB18C6 and TB21C7, respectively. ${ }^{1}$ The clean reactions and high product yields led to the expansion of the scope of this study to larger 24-membered-rings.

Thus, cesium-assisted cyclizations of bisphenol 4 with dimesylate 5 resulted in a $67 \%$ yield of tetrabenzo-24-crown-8, (9). In a literature report of the preparation of (9), the yield was $33 \%$ under different reaction conditions using a [2+2] cyclization from catechol and the ditosylate derivative from the same diol used to prepare $\mathbf{5} .^{12}$

Although crown ethers containing a three-carbon bridge are usually poorer metal salt extractants ${ }^{1}$ than two-carbon-bridged analogs, tribenzo-19-crown-6 (TB19C6, 7) was synthesized in $73 \%$ yield, which is a dramatic improvement from the $16 \%$ yield reported by Pedersen. ${ }^{1}$ Selected salts prepared from these ligands were recently reported. ${ }^{13}$

\section{Development of the synthesis of bisphenols}

Bisphenol 3 (Scheme 3) was synthesized on a 600-g scale as a stock starting reagent for other purposes, so it was not necessary to prepare this starting material for the reported work.

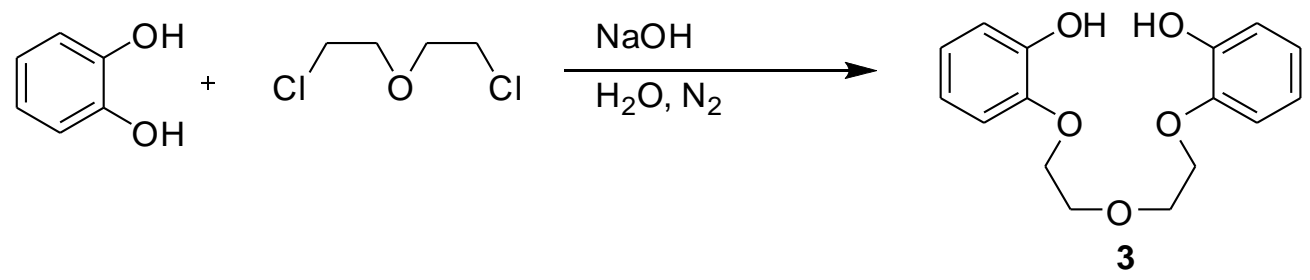

Scheme 3. Large-scale preparation of bisphenol 3. 
Protecting groups for catechol were evaluated as a precursor to bispenols. Dihydropyran was chosen as the initial protecting group for catechol, resulting in the tetrahydropyranyl (THP) acetal. The traditional method for the synthesis ${ }^{1}$ of such compounds in basic aqueous or alkanolic solvents with catechol and the dihalide of an oligoethylene glycol gave low yields with the formation of oligomeric side products. Due to the success for the cesium-assisted ring closures, this type of conditions was employed for the preparation of bisphenol 1 and $70 \%$ yields were obtained after deprotection (Scheme 4).

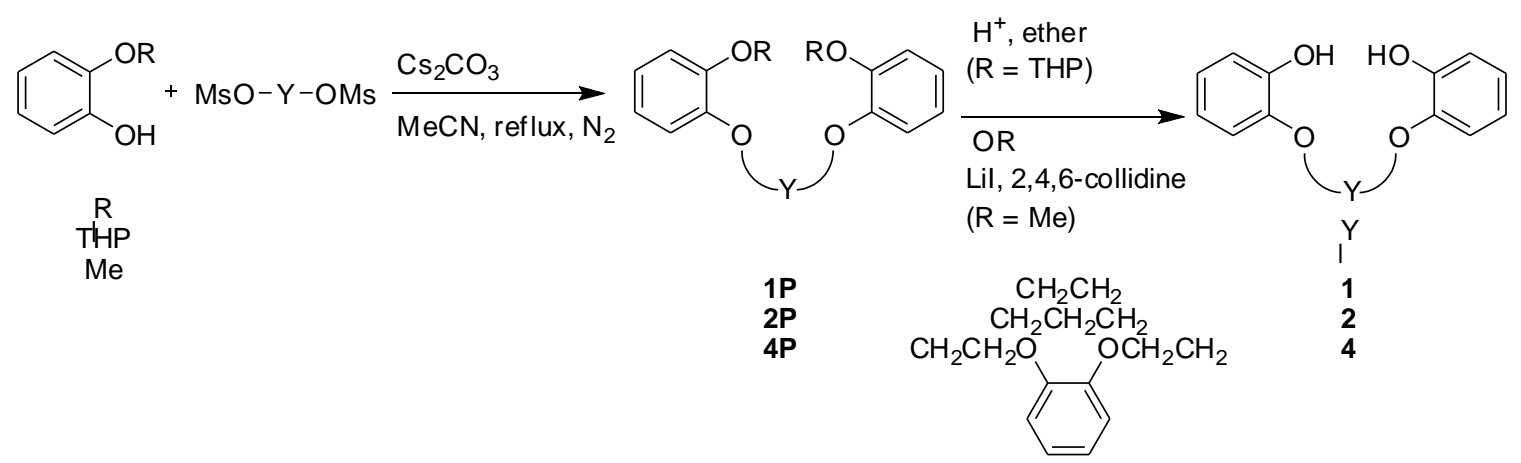

Scheme 4. Alternate synthetic routes for the preparation of bisphenols used in this work.

Since this is a statistical reaction, column chromatography was required to isolate the desired mono-protected catechol. While this was readily accomplished on alumina, it was found that upon standing, the purified mono-THP protected catechol would decompose back to catechol. This was problematic for the subsequent ring-closure reaction since it was empirically determined that the remarkably high yields were compromised by the presence of this undesired contaminant. Therefore, guaiacol (2-methoxyphenol, the commercially available, monoprotected methyl ether of catechol) would be an attractive alternative should the alklylation proceed acceptably. It should be noted that Pedersen ${ }^{1}$ mentioned guaiacol as a potential starting reactant for the preparation of crown ether compounds, but an adequate method for selective removal of the methyl protecting groups was not found.

Ether 1P was synthesized by reaction of guaiacol, the dimesylate of ethylene glycol, and cesium carbonate in $\mathrm{MeCN}$. The crystalline crude product was easily recrystallized and obtained in $90 \%$ yield. In a previous preparation, ${ }^{14}$ guaiacol was alkylated with the dimesylate of propylene glycol and $\mathrm{NaOH}$ in $\mathrm{MeCN}$ and the ether $\mathbf{2 P}$ was realized in $65 \%$ yield. In comparison, the use of cesium carbonate as the base for a similar preparation of ether $\mathbf{1 P}$ which was obtained gave a $90 \%$ yield.

Buchanan $^{15-17}$ reported the synthesis of $\mathbf{1 P}$ and $\mathbf{2 P}$ in low yields from guaiacol, the dihalide and an alkali metal hydroxide. Clearly, the use of cesium carbonate resulted in a significant improvement from the previously reported procedure. Thus the clean, high yielding alkylation with guaiacol satisfied the synthetic requirement to improve the method by avoiding mono-THPprotected catechol. 
Demethylation then became the limiting reaction for the method. A review of Greene's Protective Groups in Organic Synthesis ${ }^{18}$ provided a number of potential methyl ether cleavage reagents which might be effective in removal of the protecting methyl groups. The reagents employed resulted either in no reaction $(\mathrm{HBr} \cdot \mathrm{HOAc})$ or were not selective as multiple products were observed by TLC (trimethylsilyl iodide), suggesting cleavage at additional ether linkages. Harrison ${ }^{19}$ reported the demethylation of methyl aryl ethers using LiI in 2,4,6-trimethylpyridine (collidine) at reflux (170-171 $\left.{ }^{\circ} \mathrm{C}\right)$. When this method was employed, the desired bisphenol 1 was obtained in $80-90 \%$ yields after workup and purification. It was observed that at $150{ }^{\circ} \mathrm{C}$ the reactants dissolved and the heterogeneous mixture became homogeneous. Reaction was observed by the formation of a precipitate, presumably the di-lithium salt of the bisphenol. Analysis of the product by TLC and by ${ }^{1} \mathrm{H}$ NMR spectroscopy revealed that only the desired bisphenol was present with no evidence of other cleavage products. Despite the high temperature of the demethylation, the reaction can be described as clean.

To evaluate the method further, bisphenols $\mathbf{2}$ and $\mathbf{4}$ were also synthesized (Scheme 4). The methyl-protected ethers $\mathbf{2} \mathbf{P}$ and $\mathbf{4 P}$ were prepared in 90 and $87 \%$ yields, respectively. Demethylation of $\mathbf{2 P}$ proceeded in high yield with no evidence of additional cleavage products. Initially bisphenol 4P was obtained in 50\% yield together with multiple cleavage products, as indicated by ${ }^{1} \mathrm{H}$ NMR spectroscopy. Since dissolution of $4 \mathbf{P}$ was observed at $150{ }^{\circ} \mathrm{C}$, the deprotection reaction was repeated at this temperature in the hope that a lower temperature would reduce the formation of multiple cleavage products.

An examination of the reaction revealed the presence of a "refluxing" white solid between the solution and the condenser. It was postulated that this solid might be the $N$-methyl collidinium iodide produced by reaction of collidine with the cleavage by-product methyl iodide. If this indeed were the case, the $N$-methylcollidinium iodide would serve as an iodide source for additional demethylations. Therefore, a nitrogen gas inlet was installed into a neck of the reaction flask so that the inert gas could act as a carrier to help remove the methyl iodide through the condenser. Since the boiling point of methyl iodide is $41-43{ }^{\circ} \mathrm{C}$, it was reasonable to assume that it could be swept from the apparatus as it was formed. As a result when the reaction was repeated at $150{ }^{\circ} \mathrm{C}$ with the nitrogen inlet modification, the desired product was obtained in $64 \%$ yield with no evidence of additional cleavage products by ${ }^{1} \mathrm{H}$ NMR spectroscopy.

Due to the cost of the reagents, less expensive alternatives were sought based on literature methods and through recovery and reuse of the collidine. Bradshaw ${ }^{11}$ reported the use of $\mathrm{LiCl}$ in DMF for the demethylation of methyl aryl ethers. However, this combination of reagents failed to demethylate 1P after 24 hours at $150-153{ }^{\circ} \mathrm{C}$ as shown by TLC and ${ }^{1} \mathrm{H}$ NMR spectroscopy. Two other combinations, $\mathrm{LiCl}$ in collidine and LiI in DMF were attempted, but these reagent combinations did not demethylate $1 \mathbf{P}$ either.

To reduce the cost of the reagents, the procedure was modified to recover the collidine by high vacuum distillation instead of its removal by extraction into a highly acidic aqueous phase. The recovered collidine was purified by stirring with and distillation from solid $\mathrm{NaOH}$ under 
high vacuum distillation through a Vigreux column and was used in a demethylation reaction and found to work with no decrease in yield or purity of the product.

Although it was observed that the crude demethylated bisphenols obtained by the LiI/collidine method were essentially pure by TLC and by ${ }^{1} \mathrm{H}$ NMR spectroscopy after only an aqueous workup, the products were recrystallized since it was observed that the highest yields in subsequent ring closure reactions $(>85 \%)$ were obtained when bisphenols of high purity were employed. It should be noted that anhydrous LiI beads (99\%) were preferred over the anhydrous LiI powder because of their increased stability to oxidation. It was observed that when the LiI employed had a yellow color (presumably molecular iodine), the demethylation yield decreased. Consequently, LiI with a yellow color was heated to $120^{\circ} \mathrm{C}$ under high vacuum to remove the color. Demethylations using LiI "purified" by this method proceeded in the same high yield as with new LiI. Heating LiI to $120^{\circ} \mathrm{C}$ under high vacuum, followed by storing the salt in an amber bottle under a dry, nitrogen atmosphere is recommended.

The value of this method is realized by the high yields of valuable bisphenol precursors and the fact that oligomeric side products are avoided, in contrast to traditional methods which employ the alkylation of dihalides in basic aqueous or alkanolic solvents.

Due to the wide commercial availability of oligoethylene glycol reagents, conversion of the terminal alcohols to good leaving groups with methanesulfonyl chloride was employed. It was determined that methanesulfonyl chloride proved to be readily applied to a variety of oligoethylene glycol reagents in dichloromethane with triethylamine as the base and resulted in crude products by ${ }^{1} \mathrm{H}$ NMR spectroscopy that did not require further purification.

\section{Solid-state structures of polybenzocrown ethers}

Single crystals of $6,7,8$ and 9 were easily prepared and subjected to X-ray diffraction analysis. Sachleben et al. previously published the acetonitrile solvate of $6(6 \cdot \mathbf{M e C N})^{3}$ and the structure of 9 (identical to our structure). ${ }^{4}$ Three unique structures are reported here (Figure 1) and the crystallographic data are presented in Table 1.

Crystal structure of TB18C6 (6). Crown ether 6 crystallizes in the triclinic space group P-1 with two unique molecules in the asymmetric unit. The conformation of each unique molecule is a rather unusual folded conformation (Figure 1a) where two of the benzo substituents produce a pocket. Each unique molecule contains a disordered ethylene linkage between the nearly parallel benzo substituents which extends above the general plane of the rest of the molecule (Figure 1b). 

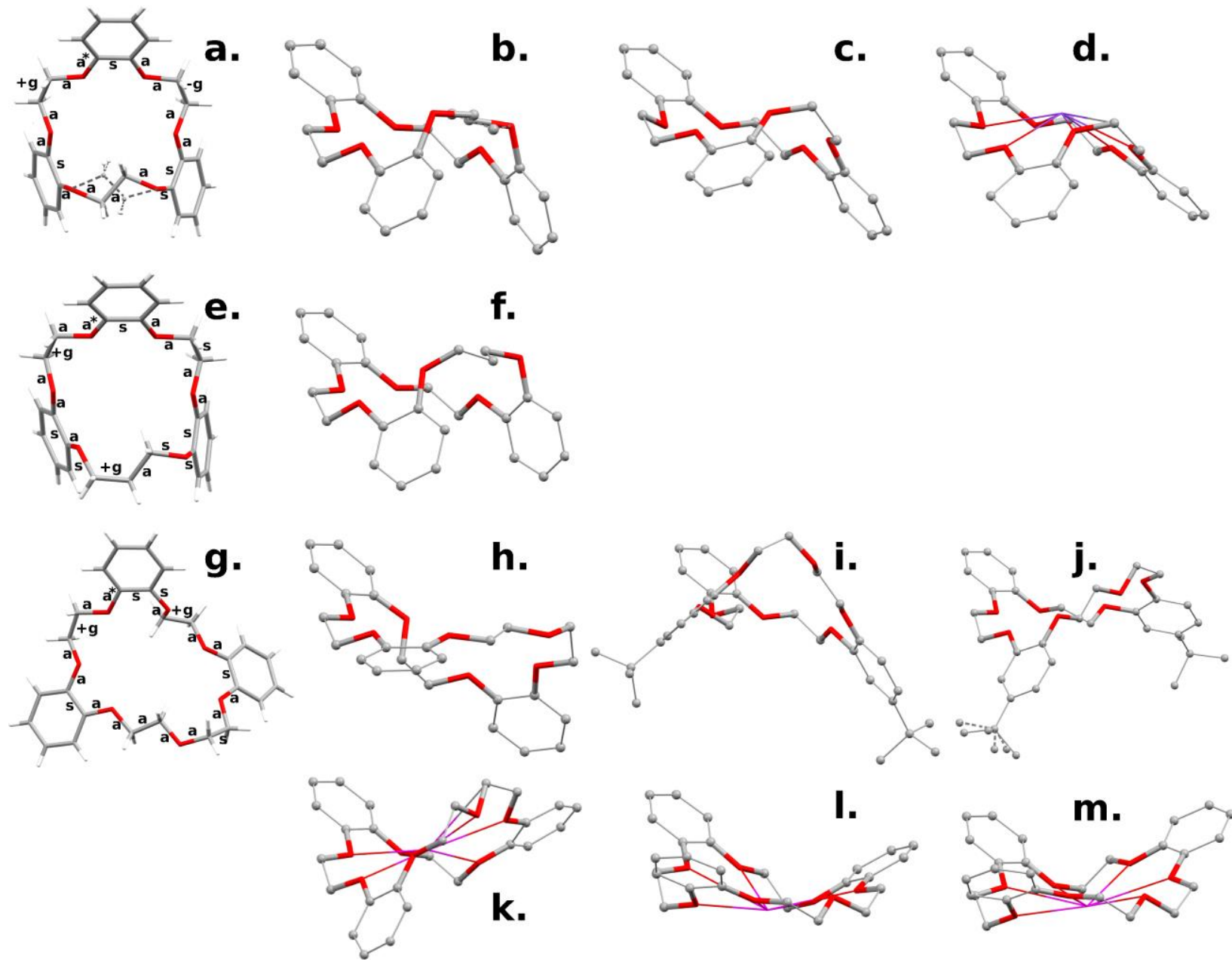

Figure 1. Crystal structures of TB18C6 (6), TB19C6 (7), and TB21C7 (8) (a, e, and g, respectively) showing torsion angle assignments around the crown ring ( $\mathrm{s}=$ synperiplanar, $\mathrm{a}=$ antiperiplanar, and $\mathrm{g}=$ gauche). To the right of each is displayed a side view of the same structures highlighting the orientations of the oxygen atoms $(b, f, h$.). The structures of tribenzo18-crown-6 $2(\mathrm{MeCN})^{3}$ and $\mathrm{K}$ [tribenzo-18-crown-6]picrate ${ }^{13}$ with solvent molecules and cation removed are shown at the end of the first row (c, d). At the end of the third row are the two unique molecules of the asymmetric unit of 4,4'-bis-tert-butylbenzo, benzo-21-crown-7 (i, j). ${ }^{20}$ The structures of $\mathrm{Rb}$ [tribenzo-21-crown-7] picrate $^{13}(\mathrm{k})$, and the two molecules in the asymmetric unit of $\mathrm{Cs}$ [tribenzo-21-crown-7] $\mathrm{NO}_{3}{ }^{20}(1, \mathrm{~m})$ with anions removed for clarity are shown in the last row. 
Table 1. Crystal and structure refinement data

\begin{tabular}{|c|c|c|c|}
\hline Compound & 6 & 7 & 8 \\
\hline Formula & $\mathrm{C}_{24} \mathrm{H}_{24} \mathrm{O}_{6}$ & $\mathrm{C}_{26} \mathrm{H}_{28} \mathrm{O}_{7}$ & $\mathrm{C}_{25} \mathrm{H}_{26} \mathrm{O}_{6}$ \\
\hline Formula weight & 408.43 & 452.48 & 422.46 \\
\hline Temperature, $\mathrm{K}$ & $173(2)$ & $173(2)$ & $173(2)$ \\
\hline Crystal system & Triclinic & Orthorhombic & Monoclinic \\
\hline Space group & $\mathrm{P}-1$ & $\mathrm{Pna}_{1}$ & $\mathrm{P} 2{ }_{1} / \mathrm{c}$ \\
\hline \multicolumn{4}{|l|}{ Unit cell dimensions } \\
\hline $\mathrm{a}, \AA$ & $8.6269(2)$ & $13.6189(2)$ & $9.0517(2)$ \\
\hline $\mathrm{b}, \AA$ & $13.9486(5)$ & $35.6785(2)$ & $8.9512(2)$ \\
\hline $\mathrm{c}, \AA$ & $17.8355(6)$ & $4.6845(1)$ & $26.6191(5)$ \\
\hline$\alpha, \operatorname{deg}$ & $100.664(2)$ & 90 & 90 \\
\hline$\beta, \operatorname{deg}$ & $95.875(2)$ & 90 & $99.554(1)$ \\
\hline$\lambda, \operatorname{deg}$ & $104.935(2)$ & 90 & 90 \\
\hline Volume & $2012.28(11)$ & $2276.21(6)$ & $2126.86(8)$ \\
\hline $\mathrm{Z}$ & 4 & 4 & 4 \\
\hline $\mathrm{D}_{\text {calc }}, \mathrm{Mg} / \mathrm{m}^{3}$ & 1.348 & 1.320 & 1.319 \\
\hline$\mu, \mathrm{mm}^{-1}$ & 0.097 & 0.096 & 0.094 \\
\hline $\mathrm{F}(000)$ & 864 & 960 & 896 \\
\hline$\theta$ range, deg & $1.18-20.83$ & $1.14-27.87$ & $1.55-27.88$ \\
\hline Reflections collected & 6901 & 11950 & \\
\hline $\begin{array}{l}\text { Independent/observed } \\
\text { refls. }\end{array}$ & $\begin{array}{l}4132 \quad\left(\mathrm{R}_{\text {int }}=\right. \\
0.0830) / 2015 \\
([\mathrm{I}>2 \sigma(\mathrm{I})])\end{array}$ & $\begin{array}{l}4950 \quad\left(\mathrm{R}_{\text {int }}=\right. \\
0.0643) / 3270 \\
([\mathrm{I}>2 \sigma(\mathrm{I})])\end{array}$ & $\begin{array}{l}4909 \quad\left(\mathrm{R}_{\text {int }}=\right. \\
0.0383) / 3399 \\
([\mathrm{I}>2 \sigma(\mathrm{I})])\end{array}$ \\
\hline Data/restraints/parameters & $4117 / 0 / 568$ & 4941/1/299 & $4909 / 0 / 281$ \\
\hline Goodness-of-fit on $\mathrm{F}^{2}$ & 0.914 & 1.274 & 1.125 \\
\hline $\begin{array}{l}\text { SHELX-93 weight } \\
\text { parameters }\end{array}$ & $0.0835,0.0000$ & $0.0151,1.4765$ & $0.0274,1.9195$ \\
\hline \multicolumn{4}{|l|}{ Final $\mathrm{R}$ indices $[\mathrm{I}>2 \sigma(\mathrm{I})])$} \\
\hline $\mathrm{R} 1$ & 0.0759 & 0.0752 & 0.0686 \\
\hline wR2 & 0.1677 & 0.1066 & 0.1168 \\
\hline \multicolumn{4}{|l|}{ Final $\mathrm{R}$ indices (all data) } \\
\hline $\mathrm{R} 1$ & 0.1551 & 0.1347 & 0.1083 \\
\hline wR2 & 0.2392 & 0.1534 & 0.1348 \\
\hline
\end{tabular}

The disordered ethylene units are characterized by unusual trans (antiperiplanar) torsion angles (Table 2), while the remaining $\mathrm{O}-\mathrm{C}-\mathrm{C}-\mathrm{O}$ torsion angles are either gauche $\left(+/-60^{\circ}\right)$, ethylene bridges or eclipsed $\left(0^{\circ}\right)$, benzo bridges. In addition, all of the torsion angles leading to the disorder are very distorted gauche ranging from -115 to $82^{\circ}$. 
Table 2. Torsion angles (degrees) for tribenzo-18-crown-6 (6), tribenzo-19-crown-6 (7), and tribenzo-21-crown-7 (8), sequenced beginning with the bond marked $\mathbf{a}^{*}$ in each representation in Figure 1

\begin{tabular}{|c|c|c|c|c|c|c|c|c|c|}
\hline \multirow[b]{2}{*}{ Ring Group } & & \multicolumn{8}{|c|}{ Molecule } \\
\hline & & \multicolumn{2}{|c|}{ TB18C6 (1), (6) } & \multicolumn{2}{|c|}{ TB18C6 (2), (6) } & \multicolumn{2}{|c|}{ TB19C6, (7) } & \multicolumn{2}{|c|}{ TB21C7, (8) } \\
\hline \multirow{3}{*}{ Benzo } & & $176.5(6)$ & $\mathrm{a}$ & $175.4(6)$ & $\mathrm{a}$ & $-178.1(2)$ & $\mathrm{a}$ & $-178.6(4)$ & $\mathrm{a}$ \\
\hline & & $0.3(9)$ & s & $1(1)$ & $\mathrm{s}$ & $-1.4(3)$ & $\mathrm{s}$ & $-0.1(6)$ & S \\
\hline & & $178.1(6)$ & $\mathrm{a}$ & $-174.3(7)$ & $\mathrm{a}$ & $-178.7(2)$ & $\mathrm{a}$ & $47.1(5)$ & $\mathrm{s}$ \\
\hline \multirow{3}{*}{ Ethylene } & & $-178.6(6)$ & $\mathrm{a}$ & $174.4(6)$ & $\mathrm{a}$ & $175.9(2)$ & $\mathrm{a}$ & $143.0(3)$ & $\mathrm{a}$ \\
\hline & & $-65.5(7)$ & $-g$ & $-68.2(7)$ & $-g$ & $-72.0(2)$ & $\mathrm{S}$ & $67.2(4)$ & $+\mathrm{g}$ \\
\hline & & $168.0(6)$ & $\mathrm{a}$ & $-177.9(6)$ & $\mathrm{a}$ & $176.3(2)$ & $\mathrm{a}$ & $169.8(3)$ & $\mathrm{a}$ \\
\hline \multirow{3}{*}{ Benzo } & & $-170.0(7)$ & $\mathrm{a}$ & $177.2(7)$ & $\mathrm{a}$ & $172.7(2)$ & $\mathrm{a}$ & $-167.7(3)$ & $\mathrm{a}$ \\
\hline & & $-4(1)$ & $\mathrm{s}$ & $-1(1)$ & $\mathrm{s}$ & $-1.5(4)$ & s & $-1.1(5)$ & $\mathrm{s}$ \\
\hline & & $82(1)$ & s & $71(1)$ & $\mathrm{s}$ & $80.0(3)$ & $\mathrm{S}$ & $178.2(3)$ & $\mathrm{a}$ \\
\hline \multirow{4}{*}{$\begin{array}{l}\text { Ethylene } \\
\text { Propylene }\end{array}$} & \multirow{4}{*}{ or } & $108.5(9)$ & $\mathrm{a}$ & $98.4(8)$ & $\mathrm{a}$ & $74.1(3)$ & s & $175.5(3)$ & $\mathrm{a}$ \\
\hline & & $-173.2(7)$ & $\mathrm{a}$ & $-179.4(7)$ & $\mathrm{a}$ & $173.8(2)$ & $\mathrm{a}$ & $77.4(4)$ & $\mathrm{s}$ \\
\hline & & $92.3(9)$ & $\mathrm{a}$ & $95.9(9)$ & $\mathrm{a}$ & $60.8(3)$ & $+\mathrm{g}$ & $-91.3(4)$ & $\mathrm{a}$ \\
\hline & & & & & & $78.0(3)$ & $\mathrm{s}$ & & \\
\hline \multirow{3}{*}{ Ethylene } & & & & & & & & $176.9(3)$ & $\mathrm{a}$ \\
\hline & & & & & & & & $-176.5(3)$ & $\mathrm{a}$ \\
\hline & & & & & & & & $177.0(3)$ & $\mathrm{a}$ \\
\hline \multirow{3}{*}{ Benzo } & & $-115.4(9)$ & $\mathrm{a}$ & $-128.4(8)$ & $\mathrm{a}$ & $-178.0(2)$ & $\mathrm{a}$ & $-170.9(3)$ & $\mathrm{a}$ \\
\hline & & $1(1)$ & $\mathrm{s}$ & $5(1)$ & $\mathrm{S}$ & $1.1(3)$ & $\mathrm{s}$ & $-4.6(5)$ & $\mathrm{s}$ \\
\hline & & $-178.8(6)$ & $\mathrm{a}$ & $177.5(7)$ & $\mathrm{a}$ & $167.6(2)$ & $\mathrm{a}$ & $156.5(4)$ & $\mathrm{a}$ \\
\hline \multirow{3}{*}{\multicolumn{2}{|c|}{ Ethylene }} & $178.8(6)$ & $\mathrm{a}$ & $-170.8(6)$ & $\mathrm{a}$ & $-164.6(2)$ & $\mathrm{a}$ & $163.3(3)$ & $\mathrm{a}$ \\
\hline & & $67.9(7)$ & $+\mathrm{g}$ & $67.4(7)$ & $+g$ & $70.0(2)$ & $+g$ & $59.0(4)$ & $+g$ \\
\hline & & $-177.1(6)$ & $\mathrm{a}$ & $-177.8(6)$ & $\mathrm{a}$ & $-176.9(2)$ & $\mathrm{a}$ & $-179.6(3)$ & $\mathrm{a}$ \\
\hline
\end{tabular}

The observed conformation, and indeed the fact that two unique molecules are observed, appear to be the result of maximization of $\mathrm{C}-\mathrm{H} \bullet \bullet \mathrm{O}$ and $\mathrm{C}-\mathrm{H} \bullet \bullet \mathrm{C}$ (aromatic edge-to-face stacking) interactions. These interactions are typified by those shown in Figure 2 where it is clear 
that the two molecules in the asymmetric unit have different hydrogen bonding environments. There are $15 \mathrm{C}-\mathrm{H} \bullet \bullet \mathrm{O}$ with $\mathrm{H} \bullet \bullet \mathrm{O}$ distances ranging from 2.43 to $2.97 \AA$ and $\mathrm{C}-\mathrm{H} \bullet \bullet \mathrm{O}$ angles ranging from 131 to $163^{\circ}$. Each unique molecule associates with a symmetry related molecule of the same type by insertion of a benzo substitutent into the molecular cleft. This benzo substitutent hydrogen interacts to a ring oxygen, but also participates in an edge-to-face interaction.

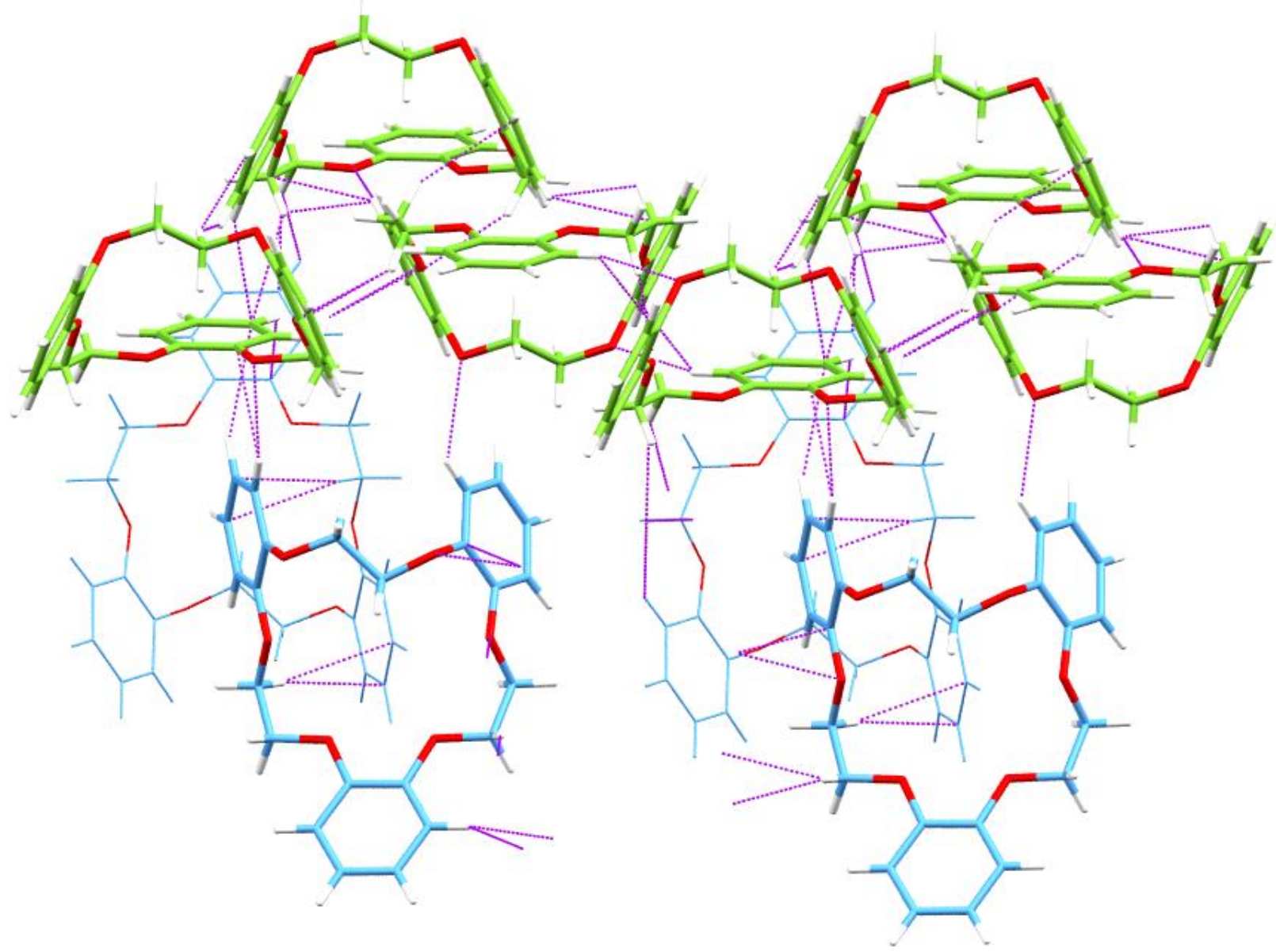

Figure 2. Selected short interactions between molecules of TB18C6 (6) in the solid state. Symmetry-related molecules are colored similarly (blue, green). Both unique molecules of the asymmetric unit pack in an interlocking fashion, but only with another symmetry-related molecule. Hanging contacts in the center of the diagram point to a fifth blue molecule that exists between the two forward darker blue molecules, but that has been made invisible to aid in viewing.

Most of the $\mathrm{C}-\mathrm{H} \bullet \bullet \mathrm{O}$ hydrogen bonds involve the aromatic hydrogen atoms, however, the hydrogen atoms on either side of the unique benzo substitutent in each crown molecule (bonded 
to $\mathrm{C} 1, \mathrm{C} 10, \mathrm{C} 25, \mathrm{C} 34)$ also are involved in the interactions with some of the shortest $\mathrm{H} \bullet \bullet \mathrm{O}$ separations: 2.66 to $2.74 \AA\left(\mathrm{C}-\mathrm{H} \bullet \bullet \cdot \mathrm{O}=131\right.$ to $\left.163^{\circ}\right)$.

The distorted boat shaped arrangement of oxygen donor atoms from the trans conformation of one O-C-C-O unit produces a long O••O (O3-O4; O9-O10) separation of $3.66 \AA$. The remaining $\mathrm{O} \bullet \bullet \mathrm{O}$ distances range from 2.59 to $2.79 \AA$.

The unusual conformations observed in the solid state are a result of maximizing the weak $\mathrm{C}-\mathrm{H} \bullet \cdot \mathrm{O}$ interactions and are unlikely to be maintained in solution. The power of such weak interactions to organize the crown ether into a specific conformation is nonetheless evident when comparing the solid state structure of $\mathbf{6} \cdot \mathbf{2 M e C N}$ (Figure 1c) to $(\mathbf{6})$. In $6 \cdot 2 \mathrm{MeCN}$, there is no disorder, no unusual trans O-C-C-O torsion angles, and all of the oxygen atoms are oriented toward the center of the crown as found for the potassium picrate salt, K6 picrate ${ }^{13}$ (Figure 1d). The complexed crown ethers exhibit significantly less folding compared to the free crown 6. K6picrate is not disordered and all of the ethylene units display normal +/-gauche conformations. All of the oxygen atoms are oriented toward the center of the crown ring to facilitate binding of the metal cation.

Crystal structure of TB19C6 (7). Crown ether (7) crystallizes in the orthorhombic space group Pna2 1 with one unique molecule in the asymmetric unit. The flexibility afforded by the replacement of an ethylene bridge in (6) with a propylene bridge in (7) allows more folding of the crown ether near the nearly planar benzo substituents (Figure 1e, f) which is more pronounced than in $(\mathbf{6})$.

The overall conformation here is also likely caused by intermolecular packing forces, as exemplified by the five molecules in Figure 3. As in (6), (7) packs in an interlocking fashion, with one of the similar benzo rings on one molecule inserting itself into the pocket formed by two folded benzo substituents of a symmetry-related molecule. The distance from the centroid of the oxygen atoms in the second molecule to the nearest aromatic $\mathrm{C}-\mathrm{H}$ of the inserted benzo substituent of the first molecule is just $2.169 \AA$. A folded benzo substituent points to this same centroid from a distance of $3.043 \AA$ on the opposite side of the crown ring. This benzo group also shows an aromatic edge-to-face interaction with the unique benzo group of the second molecule, which occurs over a distance of $2.777 \AA$. Two other possible edge-to-face interactions exist, one between each ethylene chain and an aromatic carbon within a folded benzo substituent of another molecule. 


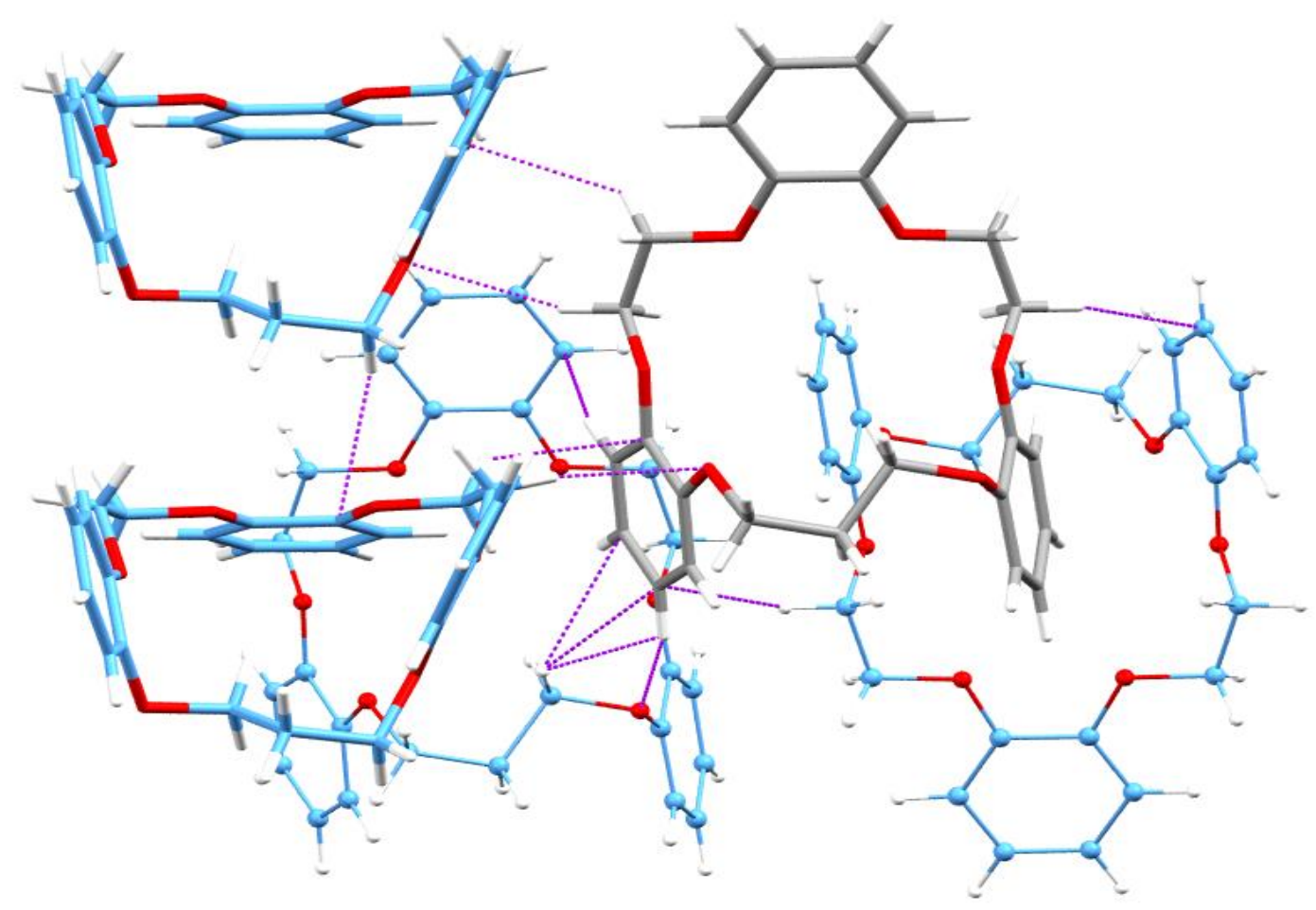

Figure 3. Selected short interactions between molecules of TB19C6 (7) in the solid state. Interactions are shown between a single molecule (gray) and four symmetry-related molecules (blue).

All of the benzo O-C-C-O torsion angles are eclipsed (cis), whereas those for the two ethylene linkages are gauche. The propylene chain has two torsion angles about $\mathrm{C}-\mathrm{C}$ bonds. One of these is anti and the other gauche (clinal). The complete sequence of torsion angles beginning with the angle about the $\mathrm{C}-\mathrm{O}$ (benzo carbon to oxygen) bond on one side of the propylene linkage and ending with the similar angle on the opposite side is $\left.\mathrm{s} \mathrm{sa}^{+} \mathrm{gs}\right) \mathrm{a}$, where the angles about the propylene bonds have been listed in parentheses (see Table 2). The asymmetry in the torsion angles across this chain can be attributed to $\mathrm{O} \bullet \bullet \mathrm{H}-\mathrm{C}$ interactions originating from the oxygen atoms at the ends of the chain. The distances of these interactions are $2.643 \AA$ and 2.668 A.

Around the main ring of the molecule, adjacent $\mathrm{O} \bullet \cdot \mathrm{O}$ distances range from $2.573 \AA$ to $2.845 \AA$, except across the propylene chain, where the distance is $4.339 \AA$. Only one of the six oxygen atoms points away from the centroid of the ring. The distance from this unique oxygen atom to the centroid of the oxygen ring is $3.509 \AA$. For the remaining oxygen atoms, these distances range from $2.590 \AA$ to $2.979 \AA$. The smallest $\mathrm{O} \bullet \bullet \mathrm{O}$ distance between an oxygen atom and it's opposite on the far side of the ether ring is $5.416 \AA$. 
Crystal structure of TB21C7 (8). Crown Ether 8 (Figure 1g, h) crystallizes in a butterfly conformation with two benzo substituents folded away from the third. The degree of folding for this crown ether is less than that seen in the other molecules presented. This allows for efficient stacking in a columnar fashion along unit cell axis $\underline{\mathrm{c}}$, such that the benzo substituents above and below interact in a face-to-face stacking fashion (Figure 4). Although all three benzo groups have identical centroid-to-centroid separations of $4.685 \AA$, the benzo group which bends away from the other two (C3, C4, C19-C22), has longer C••C contacts. The shortest such contact for this benzene ring is $4.29 \AA$, while the remaining two have much closer contacts starting at approximately $3.4 \AA$.

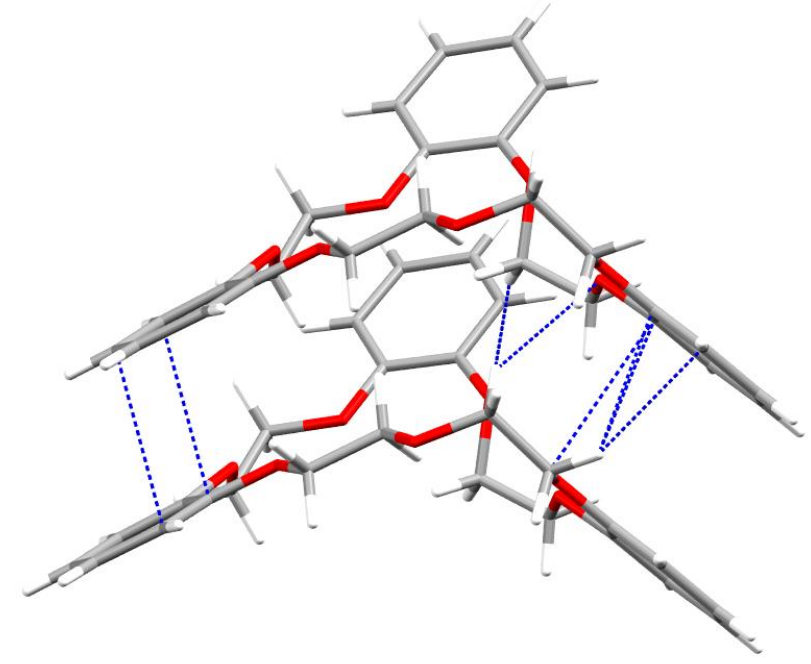

Figure 4. Short contact interactions and face-to-face stacking of TB21C7 (8).

Perhaps because of the dominance of the face-to-face stacking interactions, the predominance of aromatic $\mathrm{C}-\mathrm{H} \bullet \bullet \mathrm{O}$ hydrogen bonding observed in $\mathbf{6}$ is absent in $\mathbf{8}$. Instead there are nine weak ethylene $\mathrm{C}-\mathrm{H} \bullet \bullet \mathrm{O}$ hydrogen bonds (ranging from 2.70 to $3.08 \AA$ ) to neighboring crown molecules in the column. There are two additional such interactions $(2.71,2.81 \AA)$ and two aromatic $\mathrm{C}-\mathrm{H} \cdot \cdots \mathrm{O}$ hydrogen bonds $(2.83,2.86 \AA)$ to molecules in three neighboring columns.

The crown ether conformation is characterized by three +gauche $\mathrm{O}-\mathrm{C}-\mathrm{C}-\mathrm{O}$ (ethylene) torsion angles and one (O6-C11-C12-O7) which is anti. The three O-C-C-O torsion angles involving the benzo groups are synperiplanar and all but three of the $\mathrm{C}-\mathrm{O}-\mathrm{C}-\mathrm{C}$ torsion angles are antiperiplanar. The only exceptions to the latter are $\mathrm{C} 3-\mathrm{C} 4-\mathrm{O} 3-\mathrm{C} 5$ (47.1(5) $\left.{ }^{\circ}\right), \mathrm{C} 6-\mathrm{C} 5-\mathrm{O} 3-\mathrm{C} 4$ $\left(143.0(3)^{\circ}\right)$, and C9-C10-O6-C11 $\left(-91.3(4)^{\circ}\right)$. Efficient stacking of the benzo groups most likely provides the driving force for this conformation in the solid state.

Recently, the crystal structure of 4,4'-bis-tert-butylbenzo, benzo-21-crown-7 was reported by Bryan, et al. representing the first structural characterization of a tribenzo-21 crown-7 (Figure 
1i, j). ${ }^{20}$ Alkyl substitution of benzo substitutents is often carried out to enhance lipophilicity of the crown ether and rarely alters the extraction characteristics of the ligand. While minor conformational differences between the tert-butyl-substituted and unsubstituted tribenzo-21crown-7 are noted, overall the conformations are quite similar. Each exhibits 3 roughly gauche $\mathrm{O}-\mathrm{C}-\mathrm{C}-\mathrm{O}$ torsion angles and one anti, the latter occurring within the $(\mathrm{O}-\mathrm{C}-\mathrm{C}-\mathrm{O})_{2}$ chain for both molecules.

It is interesting to note a wide variation in the value of the clinal $\mathrm{O}-\mathrm{C}-\mathrm{C}-\mathrm{O}$ torsion angles. In 4,4'-bis-tert-butylbenzo, benzo-21-crown-7, the three angles are tightly grouped (66.6 to $69.1^{\circ}$ and average $68.5^{\circ}$. While the average of the these three angles in $\mathbf{8}$ is identical $\left(68^{\circ}\right)$, there is a much wider range of $59.0(5)$ to $77.5(4)^{\circ}$. If the weak intermolecular interactions are indeed responsible for the observed conformation in $\mathbf{8}$, it is not surprising that some minor differences are noted. The tert-butyl groups in 4,4'-bis-tert-butylbenzo, benzo-21-crown-7 do not allow the same packing arrangement as observed in $\mathbf{8}$.

From our previous work, we are able to compare the structure of $\mathbf{8}$ with the structure of the same crown as a ligand in $\mathrm{Rb}$ [tribenzo-21-crown-7]picrate (Rb7picrate, Figure $1 \mathrm{k})^{13}$. As was the case in the comparison of $\mathbf{6}$ with K6picrate, the complexed metal cation significantly reduces the folding of two of the benzo substituents; although for $\mathbf{8}$, this folding was already minimal. After complexing only one of the two substituents is left in a folded-down orientation.

There is also rearrangement of the $(\mathrm{O}-\mathrm{C}-\mathrm{C}-\mathrm{O})_{2}$ linkage. In the un-complexed structure, the two ethylene groups are clinal and anti. With the potassium cation near the center of the crown ring, they are both clinal. Again, the oxygen atoms about the ethylene groups have reoriented so that their lone pairs are directed inward toward the metal. This same trend is seen in the structure of $\mathrm{Cs}$ [tribenzo-21-crown-7] $\left(\mathrm{NO}_{3}\right)$ (Figure $\left.11, \mathrm{~m}\right)^{20}$. Interestingly, the two benzo substituents on either side of the (O-C-C-O) $)_{2}$ chain are folded slightly up for this structure, indicating that the tendency of the benzo groups to fold down in the free crown can be reversed with the addition of a metal cation.

The cavity formed by the ring oxygen atoms in $\mathbf{8}$ has a distorted boat shape, similar to that found in 6. Again the one O-C-C-O anti torsion angle produces a long O7•••O6 distance of 3.58 $\AA$. The O6 $\bullet \bullet$ O5 separation is also long at $3.02 \AA$. The remaining $\mathrm{O} \bullet \bullet \mathrm{O}$ separations range from 2.58 to $2.84 \AA$.

\section{Conclusions}

Four crown ethers were prepared by cesium-assisted cyclization and their solid-state structures were evaluated by X-ray diffraction. Through the evaluation of solid state structures, the knowledge of these ligands in their solid state furthers the understanding of these ligands as metal ion complexants when they are evaluated in solution. With the efficiency of the cesium assisted cyclization demonstrated, the preparation of starting bisphenols was improved demonstrating a robust method for the preparation of these macrocycles. 


\section{Experimental Section}

General. Reagents were purchased from commercial sources and used as received unless otherwise specified. Powdered, anhydrous cesium carbonate (99\%) was purchased from Chemmetall GMBH of Germany through CM Chemical Products, Inc. (Berkeley Heights, New Jersey). MeCN was stored over $4 \AA$ molecular sieves.

When purging of a solvent was required, nitrogen which had passed through a calcium chloride drier was forced through a glass dispersion tube submerged beneath the surface of the solution. Infrared spectra were recorded with a Perkin Elmer 1600 FT-IR spectrophotometer. The ${ }^{1} \mathrm{H}$ and ${ }^{13} \mathrm{C}$ NMR spectra were obtained with IBM AF-200 and AF300 spectrometers and chemical shifts are reported downfield from TMS. Mass spectra were obtained with a Hewlett Packard 5995 mass spectrometer using a $70 \mathrm{eV}$ ionization beam with samples introduced by direct insertion. Elemental analyses were performed by Desert Analytics Laboratory (now Columbia Analytical Services) of Tucson, Arizona.

\section{General procedure for the cesium-assisted cyclization of polybenzocrown ethers}

The ring-closure procedure was successfully performed on scales ranging from 1.0 to $7.0 \mathrm{~g}$ with respect to the bisphenol or catechol reactant. Concentrations of $0.045 \mathrm{M}$ for the catechol or bisphenol reactant and $0.090 \mathrm{M}$ for the dimesylate in $\mathrm{MeCN}$ were determined to be optimal for minimizing the formation of the [2+2] side product.

To a dry, nitrogen-flushed, three-necked flask, $\mathrm{MeCN}$ was added and purged for 15 min by forcing nitrogen through a glass dispersion tube which was submerged beneath the surface of the solvent. The bisphenol $(1.00 \mathrm{~g}, 1.0 \mathrm{eq})$ was added and the solution was purged for an additional $15 \mathrm{~min}$. Cesium carbonate ( $2.5 \mathrm{eq}$ ) was added and stirring was initiated with a bar magnet at the maximum rate of the stirring hot plate. The heterogeneous mixture was heated to reflux and stirred under nitrogen for $3 \mathrm{~h}$. A solution of the dimesylate $(1.0 \mathrm{eq})$ in $\mathrm{MeCN}(38 \mathrm{~mL})$ was added to the refluxing, heterogeneous mixture at a rate of $3 \mathrm{~mL} / \mathrm{h}$ via a syringe pump. The reaction mixture was allowed to stir for at least $12 \mathrm{~h}$ after the addition was finished. The reaction mixture was cooled to room temperature and filtered through a Celite pad in a sintered-glass funnel. The Celite pad was rinsed with $\mathrm{CH}_{2} \mathrm{Cl}_{2}(100 \mathrm{~mL})$. The combined filtrate and washing were evaporated in vacuo and the residue was dissolved in $\mathrm{CH}_{2} \mathrm{Cl}_{2}(100 \mathrm{~mL})$. The organic solution was washed with $\mathrm{HCl}(50 \mathrm{~mL}), \mathrm{H}_{2} \mathrm{O}(50 \mathrm{~mL})$ and brine $(50 \mathrm{~mL})$, then dried over $\mathrm{MgSO}_{4}$ and evaporated in vacuo. Purification was accomplished by dissolving the residue in a minimum amount of $\mathrm{CH}_{2} \mathrm{Cl}_{2}$ and pre-sorbing the solution onto activated alumina $(4: 1 \mathrm{~g} / \mathrm{g}$ adsorbent to product). The presorbed alumina was loaded onto a 20:1 adsorbent to product bed of activated alumina and the product was obtained by elution with ethyl acetate.

2,3,8,9,14,15-Tribenzo-18-crown-6 (6). White solid, 85\% yield; mp 192-195 ^ $\mathrm{C}$ (lit. ${ }^{1} \mathrm{mp}$ 190$\left.192{ }^{\circ} \mathrm{C}\right)$ IR 1255, $1127 \mathrm{~cm}^{-1} ;{ }^{1} \mathrm{H}$ NMR (200 MHz, $\left.\mathrm{CDCl}_{3}\right) \delta 6.91(\mathrm{~s}, 12 \mathrm{H}), 4.38(\mathrm{~s}, 12 \mathrm{H}) ;{ }^{13} \mathrm{C}$ NMR $\left(50 \mathrm{MHz}, \mathrm{CDCl}_{3}\right.$ ): $\delta 148.8,121.7,115.2,67.8$. MS (DIP-EI) m/e 408.30 (408.16 
Calculated for $\mathrm{C}_{24} \mathrm{H}_{24} \mathrm{O}_{6}$ ). Single crystals were prepared by slow evaporation from dichloromethane-hexanes solution.

2,3,8,9,14,15-Tribenzo-19-crown-6 (7). White solid, 73\% yield; mp 144-147 ${ }^{\circ} \mathrm{C}$ (lit. ${ }^{1} \mathrm{mp} 147$ $\left.149^{\circ} \mathrm{C}\right)$. IR 1251, $1124 \mathrm{~cm}^{-1} ;{ }^{1} \mathrm{H}$ NMR $\left(200 \mathrm{MHz}, \mathrm{CDCl}_{3}\right) \delta 6.81-6.96(\mathrm{~m}, 12 \mathrm{H}), 4.37(\mathrm{~s}, 8 \mathrm{H})$, $4.23(\mathrm{t}, 6.0 \mathrm{~Hz}, 4 \mathrm{H}), 2.16(\mathrm{p}, 6.0 \mathrm{~Hz}, 2 \mathrm{H}) ;{ }^{13} \mathrm{C} \mathrm{NMR}\left(50 \mathrm{MHz}, \mathrm{CDCl}_{3}\right): \delta 149.8,149.0,122.3$, 121.70, 121.6, 116.2, 115.0, 114.4, 68.0, 67.6, 67.5, 30.2; MS (DIP-EI) m/e 422.25 (422.17 Calculated for $\mathrm{C}_{25} \mathrm{H}_{26} \mathrm{O}_{6}$ ). Anal. calcd for $\mathrm{C}_{25} \mathrm{H}_{26} \mathrm{O}_{6}$ : C, 71.07; H, 6.20. Found: C, 70.99; H, 6.13. Single crystals were prepared by slow evaporation from dichloromethane solution.

2,3,8,9,14,15-Tribenzo-21-crown-7 (8). White solid, 84\% yield; mp 101-104 o C (lit. ${ }^{1} \mathrm{mp} 98.5$ $100 \stackrel{\circ}{\circ}$ ) IR 1256, $1127 \mathrm{~cm}^{-1} ;{ }^{1} \mathrm{H}$ NMR $\left(200 \mathrm{MHz}, \mathrm{CDCl}_{3}\right) \delta$ 6.88-6.95 (m, 12H), $\square$ 4.34-4.42 (m, $8 \mathrm{H}), 4.14-4.18(\mathrm{~m}, 4 \mathrm{H}), 3.92-3.97(\mathrm{~m}, 4 \mathrm{H}) ;{ }^{13} \mathrm{C} \mathrm{NMR}\left(50 \mathrm{MHz}, \mathrm{CDCl}_{3}\right): \delta 149.0,121.9,121.8$, 115.84, 115.7, 115.1, 69.92, 66.3, 67.9; MS (DIP-EI) m/e 452.25 (452.18 Calculated for $\mathrm{C}_{26} \mathrm{H}_{28} \mathrm{O}_{7}$ ). Single crystals were prepared through slow evaporation from dichloromethanehexanes.

2,3,8,9,14,15,20,21-Tetrabenzo-24-crown-8 (9). White solid, $67 \%$ yield; mp 146-147 ${ }^{\circ} \mathrm{C}$ (lit. ${ }^{1}$ mp 150-152 ${ }^{\circ} \mathrm{C}$ ); IR 1258, $1117 \mathrm{~cm}^{-1} ;{ }^{1} \mathrm{H}$ NMR (200 MHz, $\left.\mathrm{CDCl}_{3}\right) \delta \square 6.82-6.94(\mathrm{~m}, 16 \mathrm{H}), 4.27$ (s, 16H); ${ }^{13} \mathrm{C}$ NMR (50 MHz, $\mathrm{CDCl}_{3}$ ): $\delta 149.3,122.0,116.1$, and 68.6; MS (DIP-EI) m/e 544.20 (544.21 Calculated for $\mathrm{C}_{32} \mathrm{H}_{32} \mathrm{O}_{8}$ ). Single crystals were prepared by slow evaporation from dichloromethane-hexanes solution.

\section{General procedure for preparation of bisphenols 2, 3, 4 and 5 from the mono-THP- protected catechol 1 and dimesylates}

Mono-THP-protected catechol (1P, $11.00 \mathrm{~g}, 0.566 \mathrm{~mol}, 2.2 \mathrm{eq})$ was added to MeCN (500 mL) in a $1 \mathrm{~L}$, three-necked flask. A nitrogen purge of the solution was commenced for 15 min and a nitrogen atmosphere was maintained during the course of the reaction. Cesium carbonate (20.98 $\mathrm{g}, 0.644 \mathrm{~mol}, 2.5 \mathrm{eq}$ ) was added, and the heterogeneous mixture was heated to reflux and stirred for $3 \mathrm{~h}$. A solution of dimesylate $(0.257 \mathrm{~mol})$ dissolved in $\mathrm{MeCN}(250 \mathrm{~mL})$ was added over $8 \mathrm{~h}$. The reaction mixture was allowed to stir overnight at reflux after the addition was completed. After cooling to room temperature, the mixture was filtered through a Celite pad on a sintered glass funnel. The Celite pad was washed with $\mathrm{CH}_{2} \mathrm{Cl}_{2}(100 \mathrm{~mL})$. The combined filtrate and washings were evaporated in vacuo and the residue was dissolved in $100 \mathrm{~mL}$ of $\mathrm{CH}_{2} \mathrm{Cl}_{2}$. The organic layer was washed with distilled water $(50 \mathrm{~mL})$ and dried over $\mathrm{MgSO}_{4}$. The product was chromatographed on alumina with $\mathrm{CH}_{2} \mathrm{Cl}_{2}$ as eluent. The solvent was evaporated in vacuo, and the residue was dissolved in $200 \mathrm{~mL}$ of $\mathrm{CH}_{2} \mathrm{Cl}_{2}-\mathrm{MeOH}(2: 1$, v/v) to which 4 drops of concentrated $\mathrm{HCl}$ were added. The solution was evaporated in vacuo, and a white solid was obtained. The solid bisphenols were recrystallized by dissolution in hot ethyl acetate and addition of room temperature hexanes until cloudiness just persisted. Slow cooling to room temperature resulted in the product free from impurities.

1,2-Bis(2'-hydroxyphenoxy)ethane (2) was isolated in $86 \%$ yield. A white solid was obtained in $77 \%$ yield with a mp $112-114 \stackrel{\circ}{\circ}$ (lit. ${ }^{21} \mathrm{mp} 115-116 \stackrel{\circ}{\circ}$ ). IR (deposit from a $\mathrm{CDCl}_{3}$ solution 
onto a NaCl plate): $3410(\mathrm{O}-\mathrm{H}) ; 1220$ and $1106(\mathrm{C}-\mathrm{O}) \mathrm{cm}^{-1} .{ }^{1} \mathrm{H}$ NMR $\left(200 \mathrm{MHz}, \mathrm{CDCl}_{3}\right): \delta 4.39$ (s, 4H); $5.71(\mathrm{~s}, 2 \mathrm{H}) ; 6.83-6.95(\mathrm{~m}, 8 \mathrm{H})$.

1,3-Bis(2'-hydroxyphenoxy)propane (3). White solid. Yield $69 \%$ after recrystallization, $\mathrm{mp}$ 124-125 ㅇ (lit. ${ }^{22} \mathrm{mp} 117-118 \stackrel{\circ}{\circ}$ ). IR (deposit from a $\mathrm{CDCl}_{3}$ solution onto a $\mathrm{NaCl}$ plate): 3312 $(\mathrm{O}-\mathrm{H}) ; 1267$ and $1109(\mathrm{C}-\mathrm{O}) \mathrm{cm}^{-1} .{ }^{1} \mathrm{H}$ NMR $\left(200 \mathrm{MHz}, \mathrm{CDCl}_{3}\right): \delta 2.32(\mathrm{p}, 6.0 \mathrm{~Hz}, 2 \mathrm{H}) ; 4.24(\mathrm{t}$, $6.0 \mathrm{~Hz}, 4 \mathrm{H}) ; 5.66(\mathrm{~s}, 2 \mathrm{H}) ; 6.84-6.92(\mathrm{~m}, 8 \mathrm{H})$.

o-Di[2-(2'-hydroxyphenoxy)ethoxy]benzene (4). Yield 71\%, mp 103-105 ㅇ (lit. ${ }^{23} \mathrm{mp}$ 116-118 $\left.{ }^{\circ} \mathrm{C}\right)$. IR (deposit from a $\mathrm{CDCl}_{3}$ solution onto a $\mathrm{NaCl}$ plate): $3392(\mathrm{O}-\mathrm{H}) ; 1237$ and 1114 (C-O) $\mathrm{cm}^{-1} .{ }^{1} \mathrm{H}$ NMR (200 MHz, $\left.\mathrm{CDCl}_{3}\right): \delta 4.31-4.39$ (m, 8H); 6.70-6.95 (m, 14H).

\section{General procedure for preparation of dimethyl-protected bisphenols 2, 3, and 5 from guaiacol 6 and dimesylates}

A 3-necked, flask fitted with a water condenser was swept with dry nitrogen for five minutes. Guaiacol (5.00 g, $40.3 \mathrm{mmol}, 2.2 \mathrm{eq})$ dissolved in MeCN (100 mL) was added, and the solution was stirred slowly for $30 \mathrm{~min}$ while it was purged with dry nitrogen. Cesium carbonate (14.92 $\mathrm{g}$, $45.8 \mathrm{mmol}, 2.5 \mathrm{eq}$ ) was weighed into a beaker and added to the reaction solution under positive nitrogen pressure at room temperature. After closing the system, the rate of stirring by the bar magnet was increased to its maximum setting. The heterogeneous mixture was heated to reflux and stirred for $3 \mathrm{~h}$. The appropriate dimesylate (18.3 mmol, $1.0 \mathrm{eq})$ in MeCN (50 mL) was added slowly to the reaction mixture dropwise via an addition funnel. The reaction mixture was allowed to stir for an additional $24 \mathrm{~h}$ after the addition was completed.

The reaction solution was allowed to cool to room temperature. The heterogeneous mixture was filtered through a pad of Celite in a sintered-glass funnel. The reaction flask and the Celite pad were rinsed with $\mathrm{CH}_{2} \mathrm{Cl}_{2}$. The solution was evaporated in vacuo, and the residue was dissolved in $\mathrm{CH}_{2} \mathrm{Cl}_{2}(100 \mathrm{~mL})$. The organic solution was washed with $\mathrm{NaOH}(50 \mathrm{~mL})$, brine $(50 \mathrm{~mL})$, and distilled water $(50 \mathrm{~mL})$, dried over $\mathrm{MgSO}_{4}$ and evaporated in vacuo. The residue was dissolved in $\mathrm{CH}_{2} \mathrm{Cl}_{2}$ and added to a 1:4 ratio (weight of product to weight of alumina) of activated alumina. Evaporation in vacuo pre-sorbed the crude product onto the alumina. (A successful pre-sorbed product on alumina should use the minimum amount of alumina required to generate a free flowing powder.) The pre-sorbed alumina was placed on a column of fresh, activated alumina (20:1 adsorbent to crude product mass) and eluted with $\mathrm{CH}_{2} \mathrm{Cl}_{2}$. The dimethylprotected bisphenols were crystalline white solids which were recrystallized from ethyl acetate.

1,2-Bis(2'-methoxyphenoxy)ethane (1P). Yield 90\% after purification, mp 133-135 으 (lit. ${ }^{23}$ mp 138-140 ${ }^{\circ} \mathrm{C}$ ). IR (deposit from a $\mathrm{CDCl}_{3}$ solution onto a $\mathrm{NaCl}$ plate): 1257 and 1124 (C-O) $\mathrm{cm}^{-1} .{ }^{1} \mathrm{H}$ NMR $\left(200 \mathrm{MHz}, \mathrm{CDCl}_{3}\right): \delta 3.85(\mathrm{~s}, 6 \mathrm{H}) ; 4.41(\mathrm{~s}, 4 \mathrm{H}) ; 6.84-7.02(\mathrm{~m}, 8 \mathrm{H})$.

1,3-Bis(2'-methoxyphenoxy)propane (2P). Yield 90\% after recrystallization. White crystalline solid, mp 110-112 ㅇ (lit. ${ }^{5} \mathrm{mp}$ 113.5-114.5 ${ }^{\circ} \mathrm{C}$ ). IR (deposit from a $\mathrm{CDCl}_{3}$ solution onto a $\mathrm{NaCl}$ plate): 1256, 1123 and $1070(\mathrm{C}-\mathrm{O}) \mathrm{cm}^{-1} .{ }^{1} \mathrm{H} \mathrm{NMR}\left(200 \mathrm{MHz}, \mathrm{CDCl}_{3}\right): \delta 2.36$ (p, $\left.6.2 \mathrm{~Hz}, 2 \mathrm{H}\right)$; $3.83(\mathrm{~s}, 6 \mathrm{H}) ; 4.24(\mathrm{t}, 6.2 \mathrm{~Hz}, 4 \mathrm{H}) ; 6.82-6.97(\mathrm{~m}, 8 \mathrm{H})$. 
o-Di[2-(2'-methoxyphenoxy)ethoxy]benzene (4P). Yield 87\%. White crystalline solid, mp 117.5-118.5 ${ }^{\circ} \mathrm{C}$. IR (deposit from a $\mathrm{CDCl}_{3}$ solution onto a $\mathrm{NaCl}$ plate): $1121(\mathrm{C}-\mathrm{O}) \mathrm{cm}^{-1} .{ }^{1} \mathrm{H}$ NMR (200 MHz, CDCl $)$ : $\delta 3.84(\mathrm{~s}, 6 \mathrm{H}) ; 4.35-4.40(\mathrm{~m}, 8 \mathrm{H}) ; 6.85-7.02(\mathrm{~m}, 12 \mathrm{H})$. Anal. calcd. for $\mathrm{C}_{24} \mathrm{H}_{26} \mathrm{O}_{6}$ : C, 70.23; H, 6.38. Found: C, 70.56; H, 6.39 .

Selective demethylation of methyl aryl ethers to form bisphenols 1, 2 and 4 1,2-Bis(2'hydroxyphenoxy)ethane (1). The procedure was a modification of a published method. ${ }^{24}$ In a dry flask equipped with a water condenser, 2,4,6-collidine $(50 \mathrm{~mL})$ was added, and the flask was purged by forcing dry nitrogen through a gas dispersion tube under the surface of the solvent for $15 \mathrm{~min}$. A nitrogen atmosphere was maintained throughout the course of the reaction. The 1,2-bis(2'-methoxyphenoxy)ethane $(7,9.76 \mathrm{~g}, 35.6 \mathrm{mmol}, 1.0 \mathrm{eq})$ and lithium iodide (99\%, 10 mesh beads or anhydrous powder, $9.77 \mathrm{~g}, 7.30 \mathrm{mmol}, 2.05 \mathrm{eq})$ were added to the collidine under nitrogen. Stirring of the reaction mixture was commenced, and the reaction temperature was slowly raised $\left(\sim 10^{\circ} / 10\right.$ minutes) until a temperature of $150 \stackrel{\circ}{ } \mathrm{C}$ was obtained. (For monitoring the reaction by TLC, a small aliquot of the reaction mixture was removed, washed with $\mathrm{HCl}$ and extracted with $\mathrm{CH}_{2} \mathrm{Cl}_{2}$ to separate the crude reaction product from the collidine.) Stirring and heating were continued for $3 \mathrm{~h}$. The reaction solution was allowed to cool to room temperature. One of the glass stoppers was replaced with a rubber stopper and nitrogen balloon. The condenser was removed and the flask was transferred to a simple distillation apparatus. Then, the balloon was removed. The collidine was removed by distillation under high vacuum. At 0.8 Torr, the distillation occurred at $\sim 40^{\circ} \mathrm{C}$. After the visible collidine was removed, the heat was increased until a temperature of $50^{\circ} \mathrm{C}$ was reached, and the distillation was allowed to continue for $30 \mathrm{~min}$ to remove any traces of collidine. The solid residue was allowed to cool to room temperature. Under nitrogen $\mathrm{HCl}(250 \mathrm{~mL})$ and $\mathrm{CH}_{2} \mathrm{Cl}_{2}(100 \mathrm{~mL})$ were added, and the mixture was stirred for $15 \mathrm{~min}$. The organic layer was removed and the aqueous solution was extracted with $\mathrm{CH}_{2} \mathrm{Cl}_{2}(100 \mathrm{~mL})$. The organic layer and extract were combined and washed with $\mathrm{HCl}(2 \times 100 \mathrm{~mL}), \mathrm{H}_{2} \mathrm{O}(2 \times 100 \mathrm{~mL})$, and brine $(100 \mathrm{~mL})$, dried over $\mathrm{MgSO}_{4}$ and evaporated in vacuo. The product was analyzed by TLC and by ${ }^{1} \mathrm{H}$ NMR spectroscopy. Although the product (normally a white powder) contained a slight yellow color, it was difficult to detect any impurities by TLC and the ${ }^{1} \mathrm{H}$ NMR spectrum was consistent with the purified compound. The product was isolated in $80 \%$ yield. The mp and IR and ${ }^{1} \mathrm{H}$ NMR spectra were consistent with the data given in the previous section.

Note. It is recommended that silicon grease be used on the joints of the reaction flask because experience has shown that the ground glass joints may fuse under the reaction conditions. It is also recommended that ground glass stoppers be used in the three-necked flask because rubber stoppers react with the collidine with leaching of the color from the rubber stopper.

1,3-Bis(2'-hydroxyphenoxy)propane (2) was prepared in a similar fashion and isolated in 66\% yield. The mp and IR and ${ }^{1} \mathrm{H}$ NMR spectra were consistent with the data given in the previous section. 
$o$-Di[2-(2'-hydroxyphenoxy)ethoxy]benzene (4) was prepared in a similar fashion and was isolated in $64 \%$ yield. The $\mathrm{mp}$ and IR and ${ }^{1} \mathrm{H}$ NMR spectra were consistent with the data given in the previous section.

General procedure for the synthesis of dimesylates from prepared and commercially available diols

For dimesylation of the diols, a modified literature procedure ${ }^{11}$ was utilized. The diol $(5.0 \mathrm{~g}, 1.0$ eq) was dissolved in $\mathrm{CH}_{2} \mathrm{Cl}_{2}(100 \mathrm{~mL})$ and cooled to $0{ }^{\circ} \mathrm{C}$ under a nitrogen atmosphere. Triethylamine (2.6 eq) was diluted with $\mathrm{CH}_{2} \mathrm{Cl}_{2}(25 \mathrm{~mL})$ and added to the solution of the diol. To the stirred solution, a solution of methanesulfonyl chloride $(2.2 \mathrm{eq})$ in $\mathrm{CH}_{2} \mathrm{Cl}_{2}(25 \mathrm{~mL})$ was added to the reaction mixture at $0 \stackrel{\circ}{\circ}$, dropwise via an addition funnel. After completion of the addition, the reaction mixture was allowed to warm to room temperature over $2 \mathrm{~h}$. A $5 \%$ aq $\mathrm{HCl}$ solution was added, and the mixture was stirred for $15 \mathrm{~min}$. The biphasic mixture was decanted into a separatory funnel and the organic layer was separated. The organic solution was washed with saturated aq. $\mathrm{NaHCO}_{3}(50 \mathrm{~mL})$, distilled $\mathrm{H}_{2} \mathrm{O}(50 \mathrm{~mL})$ and brine $(50 \mathrm{~mL})$. The solution was dried over $\mathrm{MgSO}_{4}$ and the solvent was removed in vacuo. Solid products were recrystallized from $\mathrm{MeOH}$, and the products, which were oils at room temperature, were used without purification after their characterization by ${ }^{1} \mathrm{H}$ NMR and IR spectroscopy. While these dimesylates are known compounds, their physical data are rarely reported, presumably because they are typically used without purification. For example, dimesylates were reported by Reinhoudt, ${ }^{25}$ but no data were reported.

Ethylene glycol dimesylate. White solid, yield $86 \%$, mp $41-44^{\circ} \mathrm{C}$ (lit. ${ }^{11} \mathrm{mp} 43-45$ ㅇ). IR (deposit from a $\mathrm{CDCl}_{3}$ solution onto a $\mathrm{NaCl}$ plate): 1348 and $1172(\mathrm{~S}=\mathrm{O}) \mathrm{cm}^{-1} .{ }^{1} \mathrm{H}$ NMR (200 $\left.\mathrm{MHz}, \mathrm{CDCl}_{3}\right): \delta 3.10$ (s, 6H); 4.49 (s, 4H).

1,3-Propylene glycol dimesylate. White solid, yield 91\%, mp $43-45 \stackrel{\circ}{\circ}$ (lit. ${ }^{25} \mathrm{mp} 40.5-41.5 \stackrel{\circ}{\circ}$ ). IR (deposit from a $\mathrm{CDCl}_{3}$ solution onto a NaCl plate): 1350 and $1170(\mathrm{~S}=\mathrm{O}) \mathrm{cm}^{-1} .{ }^{1} \mathrm{H}$ NMR $(200$ $\mathrm{MHz}, \mathrm{CDCl}_{3}$ ): $\delta 2.20$ (p, $\left.5.8 \mathrm{~Hz}, 2 \mathrm{H}\right) ; 3.06$ (s, $\left.6 \mathrm{H}\right) ; 4.34-4.00$ (t, $\left.5.8 \mathrm{~Hz}, 4 \mathrm{H}\right)$.

1,2-Bis(2'-hydroxyethoxy)benzene dimesylate. Crystalline solid, yield 85\%, mp 139-140 ${ }^{\circ} \mathrm{C}$ (lit. ${ }^{11} \mathrm{mp} 134-136^{\circ} \mathrm{C}$ ). This compound has low solubility in most organic solvents, including the reaction solvent $\mathrm{CH}_{2} \mathrm{Cl}_{2}$. Therefore, it was recovered by filtration of the solid that had precipitated from the reaction solution and did not redissolve during the work-up. The product was recrystallized from $\mathrm{CH}_{2} \mathrm{Cl}_{2}$-hexanes for elemental analysis. (The product was used without purification for cesium-assisted ring closure after its structure was verified by ${ }^{1} \mathrm{H}$ NMR and IR spectroscopy). IR (deposit from a $\mathrm{CDCl}_{3}$ solution onto a $\mathrm{NaCl}$ plate): 1345 and $1170(\mathrm{~S}=\mathrm{O}) ; 1253,1127$ and $1078(\mathrm{C}-\mathrm{O}) \mathrm{cm}^{-1} .{ }^{1} \mathrm{H} \mathrm{NMR}\left(200 \mathrm{MHz}, \mathrm{CDCl}_{3}\right): \delta 3.12(\mathrm{~s}, 6 \mathrm{H})$; 4.25-4.30 (m, $4 \mathrm{H})$; 4.57-4.62 (m, $4 \mathrm{H})$; 6.94-6.97 (m, $4 \mathrm{H})$. Anal. calcd for $\mathrm{C}_{12} \mathrm{H}_{18} \mathrm{O}_{8} \mathrm{~S}_{2} \cdot 0.5 \mathrm{C}_{6} \mathrm{H}_{14}$ : C, 41.19; H, 5.25. Found: C, 41.23; H, 5.33.

\section{$\mathrm{X}$-ray data collection, structure determination, and refinement}

Transparent single crystals of tribenzo-18-crown-6 6, tribenzo-19-crown-6 7, and tribenzo-21crown-7 8 were mounted on a fiber and transferred to the goniometer of a Bruker SMART diffractometer equipped with a CCD area detector and using MoK $\alpha$ radiation. The crystals were 
cooled to $-100{ }^{\circ} \mathrm{C}$ during data collection by using a stream of cold nitrogen gas. The SHELXTL software package was used for each solution and refinement. ${ }^{26}$ Absorption corrections were made with SADABS. ${ }^{27}$ Each structure was refined by using full-matrix least-squares methods on $F^{2}$. The choice of the acentric space group for 7 was confirmed by subsequent solution and successful refinement of the structure. All non-hydrogen atoms were readily located and their positions refined anisotropically (except as noted for the disordered $\mathbf{6}$ below), while all hydrogen atoms were located from difference Fourier maps and isotropically refined without restraint.

There are two unique molecules of tribenzo-18-crown-6 in the structure of $\mathbf{6}$ and disorder was resolved in one ethylene linkage in each. C5-C6 and C29-C30 were resolved into a major (A) and minor (B) orientation. For C5-C6 the disorder refined to 65\%/35\%, while for $\mathrm{C} 29-\mathrm{C} 30$ it was 70\%/30\%. C11 and C12 could not be refined anisotropically. No disorder was observed in (7) or (8). The hydrogen atoms for all three crown ethers were placed in calculated positions and allowed to ride on the bonded atom with $\mathrm{B}=1.2 * \mathrm{Ueqv}(\mathrm{C})$. Refinement of nonhydrogen atoms was carried out with anisotropic temperature factors (except for C11 and C12 in 6). A summary of data collection parameters in given in Table 1.

\section{Acknowledgements}

Portions of this research conducted at Texas Tech University were supported by Grant D-0775 from The Welch Foundation of Houston, Texas.

\section{References}

1. Pedersen, C. J. J. Am. Chem. Soc. 1967, 89, 7017.

2. See 'Quantification of the 'Cesium Effect' for Preparation of Benzo- and Polybenzocrown Ethers by Macrocyclization" in this issue.

3. Bryan, J. C.; Engle, N. L.; Sachleben, R. A.; Hay, B. P. Acta Cryst. C 2001, 57, 1359.

4. Bryan, J. C.; Bunick G. J.; Sachleben, R. A. Acta Cryst. 1999, C55, 250.

5. Kellogg, R. M.; Kruizinga, W. H. J. Am. Chem. Soc. 1981, 103, 5183.

6. Topics in Current Chemistry; Ostrowicki, A.; Koepp, E.; Vögtle, F., Eds., Springer-Verlag: Berlin, 1991, 161, 39-64.

7. Mandolim, L.; Galli, C. J. Org. Chem. 1991, 56, 3045.

8. Crescenzi, M.; Galli, C ; Mandollini, L. J. Phys. Org. Chem. 1990, 3, 428.

9. Kellogg, R. M.; Kruizinga, W. H.; Dijkstra, G. J. Org. Chem. 1987, 52, 4230

10. Vögtle, F. Chem. Ber. 1985, 118, 4433.

11. Bradshaw, J. S.; Stott, P. E. Heterocycles 1981, 75, 179.

12. Brown, G. R.; Foubister, A. J. Med. Chem. 1983, 26, 590. 
13. Talanova, G. G.; Elkarim, N. S. A.; Talanov, V. S.; Hanes, Jr., R. E.; Hwang, H.-S.; Bartsch, R. A.; Rogers, R. D. J. Am. Chem. Soc. 1999, 121, 11281.

14. Zhao, Q.; Bartsch, R. A. J. Poly. Sci. A., Poly. Chem. 1995, 33. 2267.

15. Buchanan, G. W.; Kirby, R. A.; Chariand, J. P. Can. J. Chem. 1990. 68, 410.

16. Buchanan, G. W.; Kirby, R. A.; Bourque, K Can. J. Chem. 1989, 67, 449.

17. Buchanan, G. W.; Kirby, R. A.; Chariand, J. P. J. Am. Chem. Soc. 1988, 110, 2477.

18. Greene, T. W.; Wuts, P. G. M. Protecting Groups in Organic Chemisty; Wiley: New York, 1991, pp 145-149.

19. Harrison, B. T. J. Chem. Soc, Chem. Comm. 1969, 616.

20. Bryan, J. C.; Sachleben, R. A.; Lavis, J. M.; Davis, M. C. Inorg. Chem. 1998, 37, 2749.

21. Kellogg, R. M.; Kruizinga, W. H. J. Am. Chem. Soc 1981, 103, 5183.

22. Reinhoudt, D. N.; de Jong, F.; Tomassen, H. P. M. Tetrahedron Lett. 1979, 22, 2067.

23. Lee, J. C. Ph. D. Dissertation, Texas Tech University, 1991, pp 22-41.

24. McDowell, J. W.; Case, G. N.; Bartsch, R. A.; McDonough, J. A. Anal. Chem. 1992, 64, 3013.

25. Talma, A. G.; van Vossen, H.; Sudholter, E. J. R.; van Eerden, J.; Reinhoudt, D. N. Synthesis 1986, 680.

26. Sheldrick, G. M. SHELXTL, version 5.05, Seimens Analytical X-ray Instruments Inc., 1996.

27. Sheldrick, G. M. Program for Semiempirical Absorption Correction of Area Detector Data, University of Göttingen, Göttingen (Germany), 1996. 